\title{
A New Spiral Potato Cleaner to Enhance the Removal of Impurities and Soil Clods in Potato Harvesting
}

\author{
Volodymyr Bulgakov ${ }^{1}$, Simone Pascuzzi ${ }^{2, * \mathbb{D}}$, Semjons Ivanovs ${ }^{3}$, Zinoviy Ruzhylo ${ }^{1}$, \\ Ivan Fedosiy ${ }^{1}$ and Francesco Santoro ${ }^{2}$ (D) \\ 1 Department of Mechanics, Faculty of Construction and Design, National University of Life and \\ Environmental Sciences of Ukraine, 03041 Kyiv, Ukraine; vbulgakov@meta.ua (V.B.); \\ ruzhylo@nubip.edu.ua (Z.R.); ivan1982@i.ua (I.F.) \\ 2 Department of Agricultural and Environmental Science, University of Bari Aldo Moro, Via Amendola 165/A, \\ 70126 Bari, Italy; francesco.santoro@uniba.it \\ 3 Faculty of Engineering, Latvia University of Life Sciences and Technologies, LV-2130 Jelgava, Latvia; \\ semjons@apollo.lv \\ * Correspondence: simone.pascuzzi@uniba.it; Tel.: +39-080-544-2214
}

Received: 5 October 2020; Accepted: 20 November 2020; Published: 24 November 2020

\begin{abstract}
Sustainability in the agricultural field suggests the conservation and maintenance of a natural environment of soil. Nevertheless, in the potato production chain, the mechanized harvest is carried out with the concurring removal of impurities and fertile soil. The authors have developed a new spiral potato cleaner which is able to capture and efficiently remove soil lumps of various sizes and shapes, as well as various plant residues. Theoretical and experimental studies have been performed on this soil clod cleaner to determine the structural and kinematic parameters that provide efficient capturing, motion and sifting down of the soil, through the gaps between the helices of its cleaning spirals. An analytical description of the motion of the clod of soil has been made and a system of differential equations has been compiled, whose numerical solution made it possible to determine the indicated reasonable operative parameters of the developed spiral potato cleaner. The results of the experimental research confirmed those ones obtained through the numerical solution of the mathematical model, i.e., rational angular speed $\omega$ of the rotation of the spirals from 20.0 to $30.0 \mathrm{rad} \mathrm{s}^{-1}$ and the radius $R$ of spirals between 0.12 and $0.15 \mathrm{~m}$.
\end{abstract}

Keywords: potatoes; tuber cleaning; kinematic; spiral separator; soil structure

\section{Introduction}

Sustainability is a key concept in relevant social, economic and political activities, which therefore have to aim at safeguarding the environment and natural resources [1]. In the agricultural sector, the sustainable approach requires the conservation and maintenance of a natural environment of soil, a subject closely related to the technologies used during cultivation and harvesting [2]. Nevertheless, research studies carried out within the potato cultivation sector highlighted the low tendency of the farmers to employ sustainable agricultural techniques [3]. An important phase in the potato production chain is the mechanized harvest, which is carried out with the concurring removal of impurities and fertile soil [4,5]. As is known, the potato is an irreplaceable ingredient of the food tradition of many countries and is cultivated at all latitudes, from areas close to the Arctic Circle to the southern end of the South American continent [6,7]. Europe was the greatest potato producer in the world for most of the twentieth century and currently, while accounting for $38.5 \%$ of the world's production, it has been overtaken by Asia (42.4\%) [8]. On the other hand, the Ukraine was the third largest potato producer in the world in 2018, with more than 22,503,970 Mg [8]. 
The typology of the machine used in carrying out the mechanical harvesting of the potatoes plays an important role, as the harvesters scoop out a crucial quantity of soil that is hauled up with the tubers, not making this operation sustainable from an environmental point of view [9]. Furthermore, at the time of harvest, the soil moisture, which is usually about $7-20 \%$, depending on the planting conditions, makes it even more difficult to separate the potato tubers from the soil. [10,11]. Therefore, the technological process of cleaning potatoes from the soil admixtures and the plant residues during harvesting is a complex of operations to capture and remove the free soil of clods (small particles of soil), large blocks and stones from the cleaning zone, to capture and forcibly eliminate the plant residues (rhizomes, particles of leaves and other plant admixtures), as well as to clean the potato tubers themselves from the adhered soil $[12,13]$. The technical solutions currently adopted by the commercial potato harvesters to remove the soil and impurities do not always supply efficient levels of separation of both soil and impurities [14]. This probably occurs as a result of close adhesion of moist soil to the surfaces of the separating working bodies [14]. Conversely, the technical systems, which are more vigorous on the removal of the soil, can cause damage to the tubers [15]. Furthermore, similar to what happens to other agricultural equipment, the aspects linked to the safety and health of operators should not be neglected [16-21]. The basic requirements for these operations are to not damage the potato tubers and to avoid losses [14]. Taking into account other requirements for increasing the efficiency of potato harvesting, the separation of tubers from admixtures is still a considerably complicated technical task. Consequently, a significant scientific and technological challenge is the hunt for innovative machines that can clean the soil off the heap of potatoes during harvesting [14]. The designs of the modern potato harvesters have significant differences in their principal cleaning tools (the bar elevators, swinging screens, swinging sieves, gravity cleaners, various drum and rotary separators) installed in series, starting from digging and ending with unloading, which carry out the whole process of separation from the admixtures during a long period of time [22]. However, numerous studies have found that the duration of the potato tubers on the cleaning tool is directly proportional to the application of blows, cuts, cracks and other damages to the potato tubers, which significantly reduce their quality and increase their physical loss [3,4]. The authors developed a wide range of improved potato cleaners from the soil and plant admixtures of the spiral type, for which patents from the Ukraine were granted [23]. Against this backdrop, this study aims to substantiate the structural and kinematic parameters of a new spiral-type potato cleaner developed by the authors to ensure the rapid removal of the large soil admixtures from the supplied heap and to improve the cleaning quality of the tubers. In particular, in this paper, a theoretical analysis was performed concerning: (i) the clod of soil located on the helices of the cleaning spiral and its forward movement along the helices; (ii) the loss of the mass of the clod of soil under the action of a system of external forces and the final sieving downward. Field tests were then carried out to validate the obtained numerical model.

\section{Materials and Methods}

\subsection{New Spiral Potato Cleaner Developed}

The structural and technological scheme of the basic model of the new spiral potato cleaner from admixtures, developed by the authors, containing three cleaning spiral springs, is presented in Figure 1. The spiral-type potato heap cleaner consists of three successively placed cleaning spirals (1 in Figure 1) forming the cleaning surface of a wavy shape. These cleaning spirals are mounted as cantilevers in a manner that one end of each spiral is fixed on the hubs (2 in Figure 1) connected to the driving shafts ( 3 in Figure 1), while the other ends are freely located. Moreover, the cleaning spirals (1 in Figure 1) are placed with mutual overlap, but the driving shafts ( 3 in Figure 1) provide their rotation with the same angular speeds in one direction. The cleaning spirals are installed on the hubs ( 2 in Figure 1 ) and the driving shafts ( 3 in Figure 1) with eccentricity, which makes it possible to activate the oscillations of the springs themselves in a longitudinally vertical plane. A feeding conveyor (4 in Figure 1 ) is connected to one side of the indicated cleaning surface formed by spirals (1 in Figure 1), and an unloading conveyor 
(5 in Figure 1) is located on the opposite side. The lateral sides around the cleaning spirals, in the upper part, are closed with rectangular flat protective screens (6 in Figure 1). This spiral potato cleaner from admixtures works in the following way [24]. The feeding conveyor continuously supplies a layer dug from the soil, containing the potato tubers, the plant admixtures (rhizomes, residues), solid soil clods and stones to the cleaning surface, formed by three cleaning spirals. As a result of falling from a little height, the soil layer with the potato tubers is partially destroyed and is dispersed, first on the cleaning spiral closest to it, and then it passes onto the other spirals. The cleaning spirals are mounted as cantilevers; therefore, under the action of a variable load, their free ends make oscillatory movements in the longitudinal-vertical plane. As a result, their upper parts have a variable pitch between the turns, which allows capturing and partially holding the potato tubers and the solid soil clods. However, since the cleaning spirals are connected through the hubs with the driving shafts, the cleaning spirals, by making rotational movements, capture the potato tubers and the solid soil clods with their helices and start their transportation. In this case, only the bodies of the potato tubers and the large clods of soil that are transported are held by the helices of each cleaning spiral. The transportation of the potato tubers and clods of soil takes place both in the axial direction of each cleaning spiral and partially in their radial directions. However, due to the significant gaps (between the helices of each cleaning spiral and the space between the spirals themselves), the small soil particles and short plant residues in significant quantities are immediately sieved down into the middle of the spirals and further beyond the cleaner; but on the cleaning surface, especially that which is closer to the unloading conveyor, only the potato tubers and large clods of soil remain. Thus, the potato tubers and the soil lumps, being solid bodies, are transported with a guarantee by the helices of the spirals in the direction of the longitudinal axes of the cleaning spirals themselves.

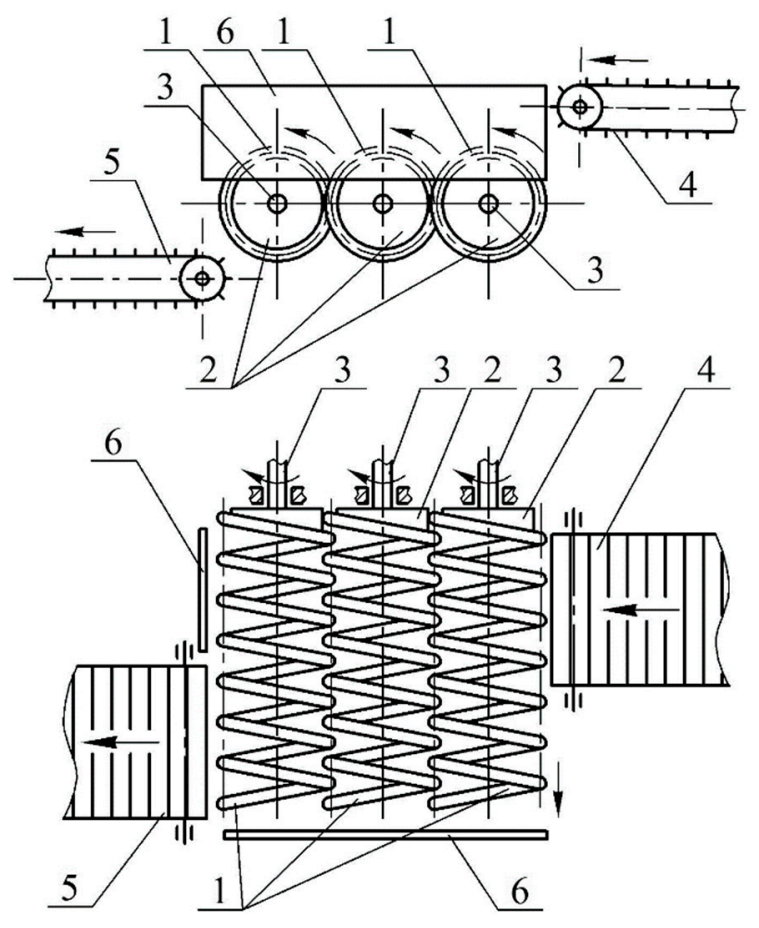

Figure 1. Lateral view and above view of the machine.

\subsection{Theoretical Study}

To build a mathematical model of the motion and sifting of a soil clod along the surface formed by cleaning spirals, an equivalent scheme was first developed, which shows only two spirals (Figure 2). These cleaning spirals are cantilevered at one of their ends at points $D$ and $D_{1}$ and their axes are parallel. Furthermore, their other ends are freely located and their oscillating movements during the 
operation of the cleaner can be produced under the action of a variable load caused by the potato heap, which proceeds around the spirals and has a variable mass. In addition, the cleaning spirals make rotational movements with the same angular velocities in one direction, which is shown in the equivalent diagram by arrows. The cleaning spirals are made in the form of cylinders having radii $R$, their helices have pitch $S$ and are directed to one side (also shown in the diagram by arrows). Finally, the spirals are arranged so that there is a mutual overlap. The helix angle of the cleaning spirals is $\gamma$. The centers of the spirals themselves are shown in the equivalent diagram by points $O$ and $O_{1}$.

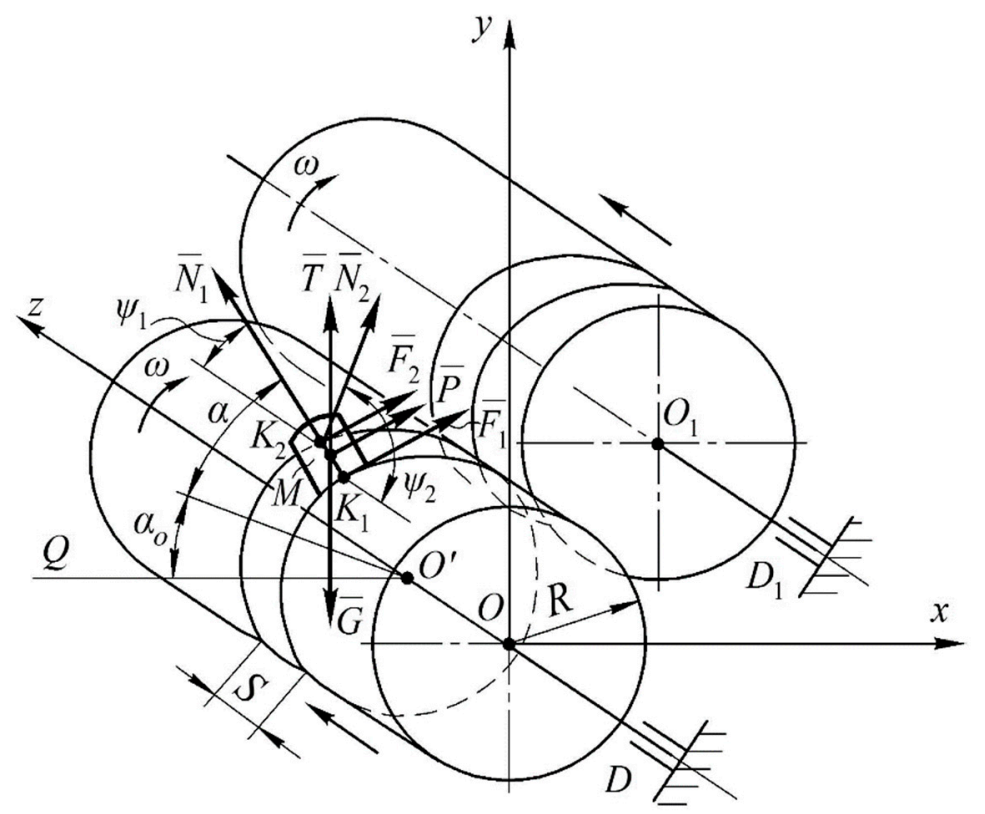

Figure 2. Equivalent scheme of the motion and sifting of a clod of soil around the surface of the spiral-type potato cleaner, being in contact at two points of the helices of the cleaning spiral.

Again, the lump of soil $M$ of an arbitrary shape that has fallen onto one of the cleaning spirals as a body of variable mass is at an arbitrary moment of time $t$ in a cavity between two adjacent helices of one spiral and contacts these helices at points $K_{1}$ and $K_{2}$ (Figure 2). It is this case of contact of the clod of soil $M$ of arbitrary shape with the surface of the cleaning spiral which, in our opinion, is the most probable. In addition, regardless of the place of the spiral itself, the indicated clod of soil $M$ will be located at the beginning of the spiral or closer to its cantilever end; the conditions for it being there will be approximately the same.

The authors have previously carried out theoretical research on the motion of a clod of soil initiated by the cleaning spiral, when the contact of the clod with the helix of the cleaning spiral takes place only at one point [14]. However, that was the most partial case, whereas the most probable case is the motion of the clod of soil caused by the helices of the cleaning spirals when the clod of soil comes into contact with the helices of the spiral at two points, without falling immediately down into the interior space of the spiral.

The construction of a mathematical model, i.e., a theoretical study of the motion and sifting of body $M$ on the surface of this spiral-type potato cleaner, is based on the application of the basic principles of dynamics of the motion of a body of variable mass [24-26]. To compose a differential equation of the motion of a body of variable mass, in our case we consider on the equivalent diagram the spatial Cartesian coordinate system $x O y z$. The origin of this $x O y z$ coordinate system is located at point $O$, which is placed on the longitudinal axis of the cleaning spiral. In this case, the $O z$ axis coincides with the longitudinal axis of the spiral itself, but the other two axes, $O x$ and $O y$, are in the plane of the cross-section of the spiral. Axis $O x$ is directed horizontally to the right, i.e., perpendicular to axis $O z$, but axis $O y$ is directed vertically upward and is also perpendicular to plane $z O x$. This coordinate 
system $x O y z$ is absolute and it is in this coordinate system that the motion of a body (a clod of soil of an arbitrary shape) of variable mass is considered.

In addition to coordinates $x, y$ and $z$ in the absolute coordinate system $x O y z$, which determine the position of body $M$ on the helices of the spiral, additional parameters are introduced, i.e., angles $\alpha_{0}$ and $\alpha$, which determine the position of body $M$ of variable mass in the cross-section of the cleaning spiral itself, taking into account that the spiral has the shape of a cylinder of radius $R$. Thus, $\alpha_{0}$ is the angle that indicates the initial position (at $t=0$ ) of points $K_{1}$ and $K_{2}$ of contact of the soil clod $M$ with the neighboring helices of the spiral in the considered cross-sections of the spiral. In this case, the first cross-section passes through point $K_{1}$, crossing axis $O z$ at point $\mathrm{O}^{\prime}$, the other cross-section passes through point $K_{2}$ parallel to the first section (not shown in Figure 2). Then, angle $\alpha_{0}+\alpha$ indicates the position of the contact points $K_{1}$ and $K_{2}$ of the clod of soil at an arbitrary moment in the indicated cross-sections, respectively. We measured angle $\alpha_{0}$ starting from a horizontal beam $O^{\prime} Q$ parallel to axis $O x$, in the direction of rotation of the spiral (in this case, clockwise). Angle $\alpha$ is measured after angle $\alpha_{0}$ in the same direction. Under these conditions, if $t=0$, then also $\alpha=0$. We also assume that the current mass of body $M$ is a function of time $t$, i.e., $m=m(t)$, and its initial value will be equal to $m_{0}$.

Referring to the equivalent scheme (Figure 2), all the external forces that act upon body $M$ of variable mass during its motion, captured by the helices of the cleaning spiral, are the following:

- $\bar{G}$ is the force of the weight of body $M$ of variable mass. This force is applied in the center of the mass of the body studied, directed vertically downward and numerically equal to:

$$
G=m(t) \cdot g
$$

where:

- $g$ is the acceleration of gravity;

- $\bar{N}_{1}, \bar{N}_{2}$ are the normal reactions of the adjacent helices of the spiral, at the contact points $K_{1}$ and $K_{2}$, respectively. They are directed, respectively, at angles $\psi_{1}$ and $\psi_{2}$ to axis $\mathrm{Oz}$ and are located in a plane, parallel to plane zOy;

- $\quad \bar{F}_{1}, \bar{F}_{2}$ are the forces of friction. These forces are directed along the tangents to the surface of the spiral helices, applied, respectively, at points $K_{1}$ and $K_{2}$ of contact to the side, opposite to the relative speed of the motion of body $M$ and, as is known, will numerically equal:

$$
F_{i}=f \cdot N_{i}, \quad i=1,2, \ldots
$$

where:

- $\quad f$ is the coefficient of friction of body $\mathrm{M}$ sliding along the surface of the spiral helices and $N_{i}$ is the normal reaction of the helices of the working surface of the spiral;

- $\quad \bar{T}$ is the force from the acceleration of the oscillating motion of the cleaning spiral, arising due to the presence of deflection of the longitudinal axis of the spiral under the action of the weight of the entire potato heap, entering on the cleaning surface.

The value of force $\bar{T}$ is determined by such an equation:

$$
T=m(t) \cdot \omega^{2} \cdot A \cdot \sin \left(\alpha_{0}+\omega t\right)
$$

where:

- $\quad A$ is the amplitude of oscillations and $\omega$ is the angular velocity of rotation of the spiral.

Force $\bar{T}$ is applied in the center of the mass of the clod of soil $M$ and at an arbitrary moment of time $t$ is directed along the normal to the helix of the cleaning spiral. 
To compose the differential equation of the movement of body $M$ of variable mass, the theorem on the change in the kinetic momentum of a material point in a differential form is applied [27-29]. In a general case, we have:

$$
\frac{d}{d t}(m \bar{V})=\sum_{k=1}^{n} \bar{F}_{k}
$$

where:

- $\quad m=m(t)$ is the mass of a material point (in this case, the mass of body $\mathbf{M}$ );

- $\quad \bar{V}=\bar{V}(t)$ is the velocity of a material point;

- $\quad \sum_{k=1}^{n} \bar{F}_{k}$ is the geometric sum of external forces that act upon a material point (conditionally, upon a material body M) at an arbitrary moment of time $t$.

After the substitution of all the above forces into Equation (4), we have:

$$
\frac{d}{d t}[m(t) \cdot \bar{V}(t)]=\bar{G}+\bar{N}_{1}+\bar{N}_{2}+F_{1}+\bar{F}_{2}+\bar{T}
$$

or:

$$
m \frac{d \bar{V}}{d t}+\bar{V} \frac{d m}{d t}=\bar{G}+\bar{N}_{1}+\bar{N}_{2}+F_{1}+\bar{F}_{2}+\bar{T}
$$

Since the mass of the body (the clod of soil $M$ ), located on the surface of the spiral-type potato cleaner, decreases over time $t$, that is:

$$
\frac{d m}{d t}<0
$$

Then, taking into account Equation (7), we write Equation (6) in the following form:

$$
m \frac{d \bar{V}}{d t}=\bar{G}+\bar{N}_{1}+\bar{N}_{2}+F_{1}+\bar{F}_{2}+\bar{T}-\bar{V} \frac{d m}{d t}
$$

The term $-\bar{V} \frac{d m}{d t}$ contained in Equation (8) is a reactive force $\bar{P}$ arising from a decrease in the mass of body $M$. It is due to a decrease in the body mass that this force $\bar{P}$ is directed towards the movement of the body and contributes to the increase in its velocity.

Since body $M$ of the variable mass moves along the surface of the cylinder, force $\bar{P}$ will also be directed tangentially to this surface.

The resulting Equation (8) is the differential equation of the motion of a body of variable mass-a material point $M$ (a clod of soil of arbitrary shape) along the surface of the spiral of the potato cleaner in a vector form.

After a series of transformations (Appendix A), from Equation (8) it is possible to obtain the nonlinear differential Equation (9), which models for the change (in this case, the decrease) in the mass of the clod of soil $M$ during time $t$, which occurs under the action of the forces applied to it, shown in the equivalent diagram (Figure 2), taking into account the structural and kinematic parameters of the spiral potato cleaner.

$$
\begin{aligned}
& \frac{d m}{d t}=\frac{2 \pi\left(N_{1} \cos \psi_{1}-N_{2} \cos \psi_{2}\right)}{S \omega}+\frac{\pi \cdot R \cdot \tan \gamma}{S} \cdot\left\{m \cdot \omega \cdot\left[\frac{1}{\tan \left(\alpha_{0}+\omega t\right)}+\tan \left(\alpha_{0}+\omega t\right)\right]+\frac{m \cdot \omega \cdot A}{R}\right. \\
& \cdot\left[\frac{\sin ^{2}\left(\alpha_{0}+\omega t\right)}{\cos \left(\alpha_{0}+\omega t\right)}-\cos \left(\alpha_{0}+\omega t\right)\right]-\frac{m \cdot g}{\omega \cdot R \cdot \cos \left(\alpha_{0}+\omega t\right)} \\
&\left.+\left(N_{1} \sin \psi_{1}+N_{2} \sin \psi_{2}\right) \cdot \frac{1}{\omega \cdot R} \cdot\left[\tan \left(\alpha_{0}+\omega t\right)-\frac{1}{\tan \left(\alpha_{0}+\omega t\right)}\right]\right\}
\end{aligned}
$$

In the presented form, this differential equation can be solved numerically and, therefore, further analysis of the solution can be made and rational design and kinematic parameters of the spiral-type 
potato heap cleaner can be obtained at which the reduction and, consequently, the screening of admixtures, i.e., the mass of clods of soil, coming together with a heap of potatoes to the cleaning surface, will occur efficiently.

Equation (9) has been solved numerically, considering the following initial conditions: at $t=0$ : $m=m_{0} ; \alpha_{0}=\frac{\pi}{4}$.

Furthermore, the following structural and kinematic parameters of the developed spiral potato heap cleaner, have been taken into account: $m_{0}=0.2 \mathrm{~kg} ; R=0.15 \mathrm{~m} ; S=0.035 \mathrm{~m} ; \gamma=20^{\circ} ; \omega=10,20,30$, $40,50 \mathrm{rad} \mathrm{s}^{-1} ; A=0.005 \mathrm{~m}$.

The numerical solution of Equation (9) has been carried out considering the soil clod (a body of variable mass $M$ ) located symmetrically in the cavity between two adjacent helices of the spiral, conditionally assuming that the soil clod had a shape close to a sphere and then $\psi_{1}=\psi_{2}=\frac{\pi}{4}$.

\subsection{Experimental Test}

To verify the correctness of the conducted theoretical research, we made experimental tests of the spiral-type potato cleaner under the field conditions using specially designed and built equipment which allowed us to immediately supply the potato heap, dug from the soil, to the developed potato cleaner (Figure 3 reports a general view of this equipment, attached to the rear linkage of the aggregating wheeled tractor.

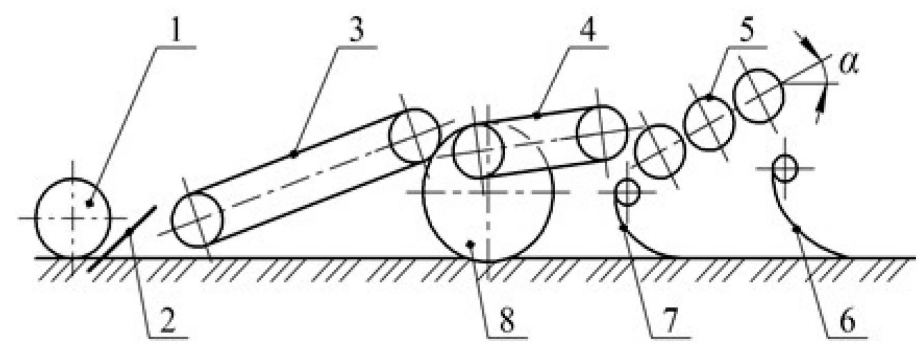

Figure 3. The scheme of the experimental equipment: 1 -the roller finder; 2 -the digging ploughshare; 3-the first receiving elevator; 4-the second receiving elevator; 5 -the spiral-type cleaner; 6 - the sheet for sampling the heap that has passed through the cleaner; 7-the sheet for sampling admixtures that have passed down; 8-the supporting wheel.

The experimental field investigations were performed during the potato harvesting season of the Ukrainian potato sort "Lugovskaya", which yielded $10.35 \mathrm{Mg} \mathrm{ha}^{-1}$, and was planted through the ridge method, with $0.70 \mathrm{~m}$ inter-row spacing in black soil (so-called chernozem) having an average soil moisture content of $11 \%$ and hardness, equal to $0.3 \mathrm{MPa}$. In addition, the weediness within the plot of the potato field, on which the experimental studies were carried out, was about $2.8 \mathrm{Mg} \mathrm{ha}^{-1}$.

The experimental tests were carried out keeping stationary the aggregating tractor of class 1.4, to which the specially arranged equipment with the spiral-type potato heap cleaner was linked by the 3 point linkage and the power take-off shaft at $56.55 \mathrm{rad} \mathrm{s}^{-1}$, for receiving the rotational motion. In these operative conditions, previously prepared and cut out of the soil tuberous samples of an appropriate size and weight were supplied onto the surface of the cleaner (Figures 3 and 4).

During the tests, changing the removable gear wheels in the drive of the cleaner spirals, the angular speeds of their rotational movement varied from $24 \mathrm{rad} \mathrm{s}^{-1}$ to $36 \mathrm{rad} \mathrm{s}^{-1}$. In particular, the following angular velocities were considered: $\omega_{1}=24.22 \mathrm{rad} \mathrm{s}^{-1}, \omega_{2}=26.17 \mathrm{rad} \mathrm{s}^{-1}, \omega_{3}=31.43 \mathrm{rad} \mathrm{s}^{-1}$, $\omega_{4}=35.07 \mathrm{rad} \mathrm{s}^{-1}$, and $\omega_{5}=37.64 \mathrm{rad} \mathrm{s}^{-1}$. Furthermore, the following inclination angle of the cleaner to the horizon was taken into account: $\alpha_{1}=0^{\circ}, \alpha_{2}=5^{\circ}, \alpha_{3}=10^{\circ}, \alpha_{2}=15^{\circ}, \alpha_{3}=20^{\circ}$.

At each mode of the angular speed $\omega$ of the cleaning spirals and the inclination angle $\alpha$ of the cleaner to the horizon, the research was triplicated. 


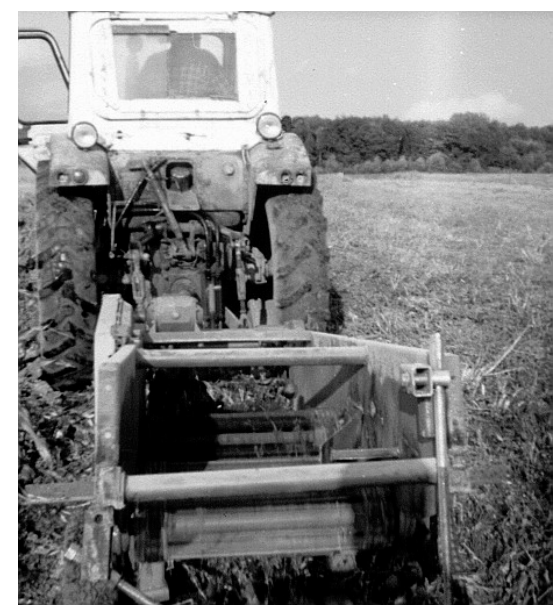

Figure 4. The experimental equipment during the field studies.

The other values of the kinematic and structural parameters of the spiral separator were kept constant, and the eccentricity value (according to the conditions for manufacturing the cleaning spirals) was $5 \mathrm{~mm}$. The main technical characteristics of the spiral-type potato heap cleaner of the new design are presented in Table 1.

Table 1. Main technical characteristics of the spiral-type potato heap cleaner.

\begin{tabular}{ccc}
\hline Indicator & Unit of Measurement & Value \\
\hline Length of the cleaner & $\mathrm{m}$ & 0.40 \\
Width of the cleaner & $\mathrm{m}$ & 0.55 \\
Number of the cleaning spirals & pieces & 3 \\
Inter-helix gaps & $\mathrm{m}$ & 0.031 \\
External diameter of the spirals & $\mathrm{m}$ & 0.133 \\
Total area of the cleaner & $\mathrm{m}^{2}$ & 0.27 \\
Area of the "effective section" of the cleaner & $\mathrm{m}^{2}$ & 0.20 \\
\hline
\end{tabular}

The experimental research allowed for studying the impact of the inclination angle $\alpha$ of the potato cleaner to the horizon and the angular speed $\omega$ of its cleaning spirals upon the output indicators of the performance of the spiral-type potato cleaner from admixtures. The experimental equipment and the aggregating tractor were adjusted for each experiment according to the corresponding values of these factors. Samples of the sifted soil passing through the potato tuber cleaner, the admixtures in the form of clods of soil and the plant residues were collected on appropriate sheets (or other containers of a reasonable size) and weighed using the precision balance KERN KB 10K0.05N (ATP Messtechnik $\mathrm{GmbH}$, Ettenheim, Germany) having the following main technical characteristics: weighing range $10,000 \mathrm{~g}$; readability $0.05 \mathrm{~g}$. Each weighing was repeated three times, and the average value was taken as the definitive value.

Throughout the field tests, the main task was to carefully take samples at various places of the experimental installation and to fix them by weighing. Therefore, the prepared samples of the potato heap were passed through the spiral-type cleaner and the components of the heap that were passed through the cleaner were collected and weighed. Based on the obtained collected and weighed samples of the sifted soil, the performance indicators of the cleaner were calculated, for which corresponding formulas were used.

To this, the following designations were introduced: (i) the total mass $m_{n}$ of soil that entered the potato cleaner, i.e., the mass that, according to the conditions of the technological process, passes through the working surface of the cleaner; (ii) the mass of soil $m_{b}$ received at the outlet of the cleaner, i.e., the mass not sifted through the soil cleaner; (iii) the mass $\Delta M$ of all the sifted soil, determined by the following equation: 


$$
\Delta M=m_{n}-m_{b}
$$

In such a way as the quality indicators by which the performance of the spiral-type potato cleaner was evaluated under stationary conditions (i.e., without its movement along the row, on condition of the supply of the previously prepared tuberous samples), the following indicators were adopted:

1. the screening ability of the cleaner $\mu$ :

$$
\mu=\frac{\Delta M}{m_{n}} \cdot 100=\frac{m_{n}-m_{b}}{m_{n}} \cdot 100
$$

2. the intensity separation of admixtures $q, \mathrm{~kg} \mathrm{~s}^{-1}$ :

$$
q=\frac{\Delta M}{\tau}=\frac{m_{n}-m_{b}}{\tau}
$$

where $\tau$ is the separation time, s.

3. the specific separation intensity $q_{n}, \mathrm{~kg} \mathrm{~s}^{-1} \mathrm{~m}^{-2}$ :

$$
q_{n}=\frac{q}{S} q
$$

where $S$ is the area of the separation surface, $m^{2}$.

\subsection{Data Analysis}

Microsoft Excel software has been employed to process the experimental data. Regression analysis concerning each quality indicator of the cleaner, by means of the least-squares method, has been performed [30]. As is known, this criterion is a technique for fitting the "best" model function $f(x)$ to a data set formed by $m$ points $\left(\hat{x}_{i}, \hat{y}_{i}\right), I=1, \ldots, m$ found by experimental observations. It includes minimizing the sum of the squared (vertical) deviations of observed points from the model function:

$$
\operatorname{Min} \sum\left(\hat{y}_{i}-f\left(x_{i}\right)\right)^{2}
$$

where

$\hat{y}_{i}$ refers to the actual observations $f\left(x_{i}\right)$ refers to the corresponding fitted values, so that $\left(\hat{y}_{i}-f\left(x_{i}\right)\right)=e_{i}$, the residual [30].

The data were processed assessing second-order polynomial regression functions, the corresponding coefficients of determination $R^{2}$ and residuals $e$. For all the examined quality indicators of the cleaner, the second-order polynomial regression functions have allowed to achieve high values of $R^{2}$ and low residuals. The second-order polynomial was given by:

$$
p(x)=a_{0}+a_{1} x+a_{2} x^{2}
$$

where the coefficients $a_{0}, a_{1}$ and $a_{2}$ were evaluated by the solution of the following matrix system [30,31]

$$
\hat{V}^{t} \hat{V} A=\hat{V}^{t} \hat{Y}
$$

where

$\hat{V}$ is the Vandermonde matrix, which contains the experimental values $\hat{V}_{i, j}=\hat{x}_{i-1}^{j-1}$,

$\hat{V}^{t}$ is the transpose matrix of $\hat{V}$,

$A$ is the column vector of the terms ai,

$\hat{Y}$ is the column vector of the experimental values $\hat{y}_{i}$. 
For example, considering the 5 couples of the experimental measures (angular speed $\omega$, mass $\Delta M$ ) obtained considering $\mathrm{a}=0^{\circ}$, the linear matrix system (16) gives:

$$
\hat{V}^{t} \hat{V}=\left(\begin{array}{ccccc}
1 & 1 & 1 & 1 & 1 \\
\omega_{0} & \omega_{1} & \omega_{2} & \omega_{3} & \omega_{4} \\
\omega_{0}^{2} & \omega_{1}^{2} & \omega_{2}^{2} & \omega_{3}^{2} & \omega_{4}^{2}
\end{array}\right)\left(\begin{array}{ccc}
1 & \omega_{0} & \omega_{0}^{2} \\
1 & \omega_{1} & \omega_{1}^{2} \\
1 & \omega_{2} & \omega_{2}^{2} \\
1 & \omega_{3} & \omega_{3}^{2} \\
1 & \omega_{4} & \omega_{4}^{2}
\end{array}\right)=\left(\begin{array}{ccc}
t_{1,1} & t_{1,2} & t_{1,3} \\
t_{2,1} & t_{2,2} & t_{2,3} \\
t_{3,1} & t_{3,2} & z t_{3,3}
\end{array}\right)
$$

and the note term of the system (16) gives:

$$
\hat{V}^{t} \hat{Y}=\left(\begin{array}{ccccc}
1 & 1 & 1 & 1 & 1 \\
\omega_{0} & \omega_{1} & \omega_{2} & \omega_{3} & \omega_{4} \\
\omega_{0}^{2} & \omega_{1}^{2} & \omega_{2}^{2} & \omega_{3}^{2} & \omega_{4}^{2}
\end{array}\right)\left(\begin{array}{c}
\Delta M_{0} \\
\Delta M_{1} \\
\Delta M_{2} \\
\Delta M_{3} \\
\Delta M_{4}
\end{array}\right)=\left(\begin{array}{c}
c_{1} \\
c_{2} \\
c_{3}
\end{array}\right) .
$$

Finally, substituting (17) and (18) in (16), it gives the following square matrix system:

$$
\left(\begin{array}{ccc}
t_{1,1} & t_{1,2} & t_{1,3} \\
t_{2,1} & t_{2,2} & t_{2,3} \\
t_{3,1} & t_{3,2} & z t_{3,3}
\end{array}\right)\left(\begin{array}{l}
a_{0} \\
a_{1} \\
a_{2}
\end{array}\right)=\left(\begin{array}{l}
c_{1} \\
c_{2} \\
c_{3}
\end{array}\right)
$$

whose solution allows to assess the coefficients $a_{0}, a_{1}$ and $a_{2}$ and then to obtain the second-order least-squares polynomial (15).

The corresponding average residual $e$ has been evaluated through the following:

$$
e=\frac{1}{5} \sum_{i=1}^{5}\left(\Delta M_{i}-f\left(x_{i}\right)\right)
$$

\section{Results and Discussion}

\subsection{Numerical Results}

Figures 5-7 report the graphical dependencies obtained by the numerical solution of Equation (9). These graphs point out that the mass of soil clod decreases by $95 \%$ in a time range from 0.08 to $0.12 \mathrm{~min}$, if structural and kinematic parameters of the developed spiral-type potato heap cleaner are suitably chosen. It should also be noted that an increase in the angular speed $\omega$ of the cleaning spirals from 30.0 to $40.0 \mathrm{rad} \mathrm{s}^{-1}$ does not contribute to a rapid change in the mass of the clod of soil, and, consequently, to an increase in the productivity of the cleaner. A similar conclusion can be made for the radius of the spirals $R$. So, accordingly, the increase from 0.10 to $0.15 \mathrm{~m}$ does not improve the sifting quality of the soil from the potato heap. A decrease in angle $\alpha_{0}$ of the initial contact of the clod of soil $M$ with the spiral cleaner has a positive impact on the separation rate of the soil admixtures from the potato heap, supplied for cleaning. 


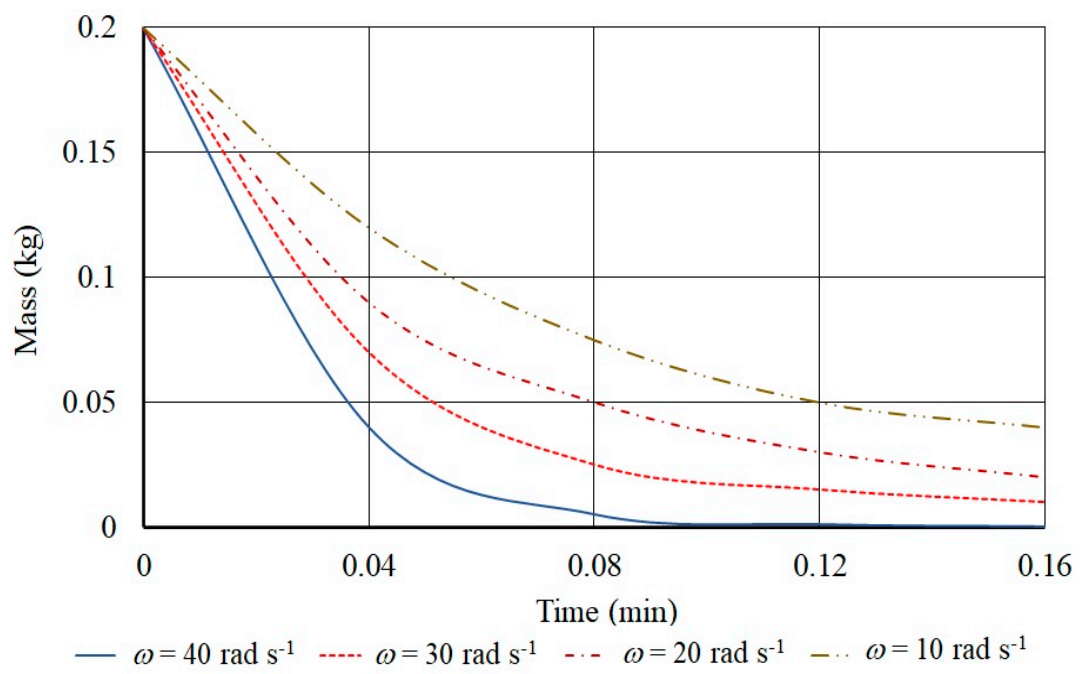

Figure 5. Change in mass $m$ of the clod of soil versus the time $t$ at different angular speeds $\omega$ of the spiral.

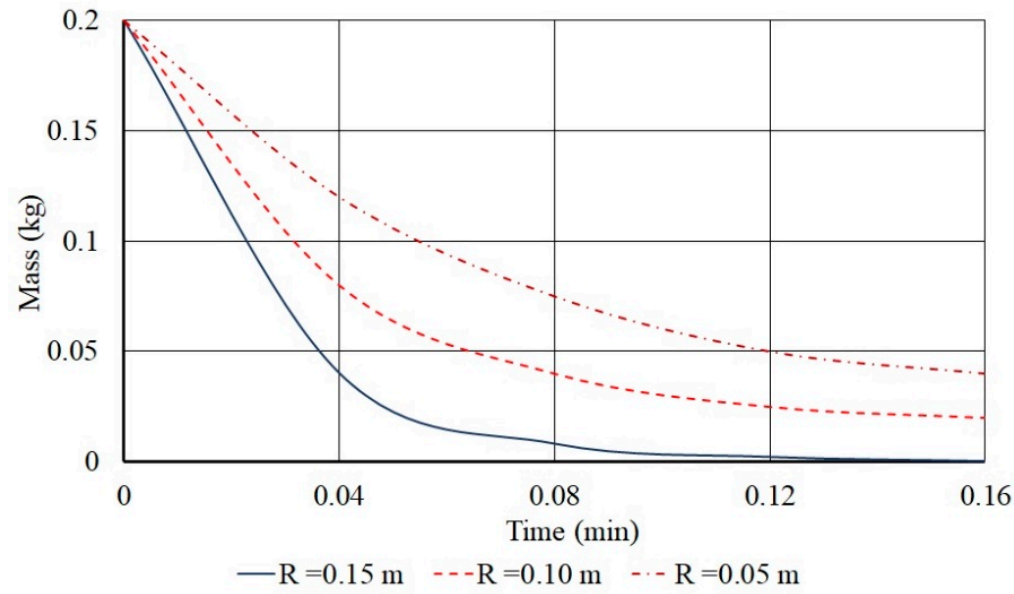

Figure 6. Change in mass $m$ of the clod of soil versus the time $t$ at different radii $R$ of the spiral.

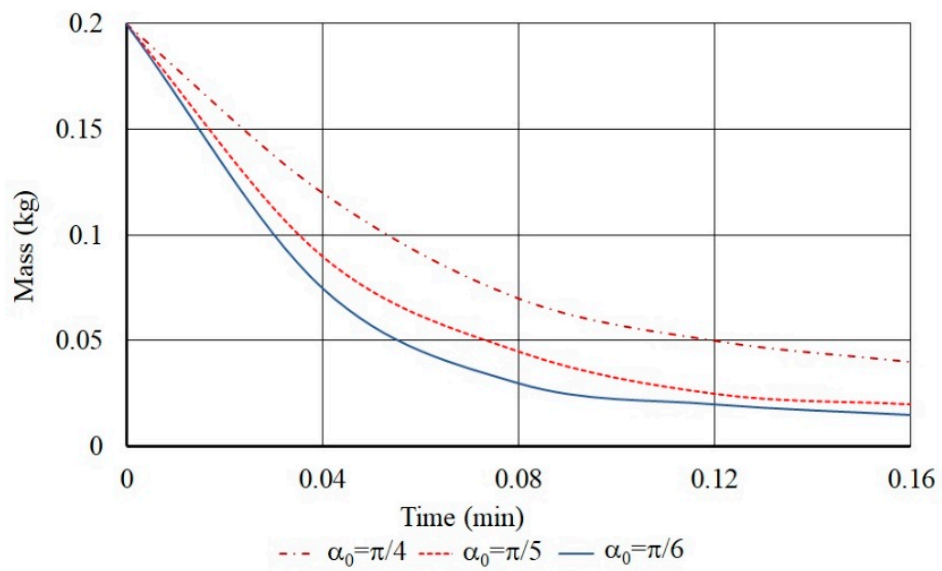

Figure 7. Change in mass $\Delta M$ of the clod of soil versus the time $t$ at different initial angles $\alpha_{0}$.

\subsection{Experimental Results}

According to the results of the experimental data analysis, dependencies were constructed from the required performance indicators of the new spiral-type potato cleaner of the design developed by us. 
Thus, dependences of the mass $\Delta M$ of the soil, sifted through the cleaner, were obtained based on the angular velocity $\omega$ of rotation of its spirals at different angles of inclination $\alpha$ of the cleaner to the horizon (Figure 8). On the subject, Table 2 reports, for each considered inclination angle $\alpha$, the second-order polynomial regression about the change in mass $\Delta M$ of the soil on the angular speed $\omega$ of the spirals, with the corresponding $\mathrm{R}^{2}$ value and residual average value $e$.

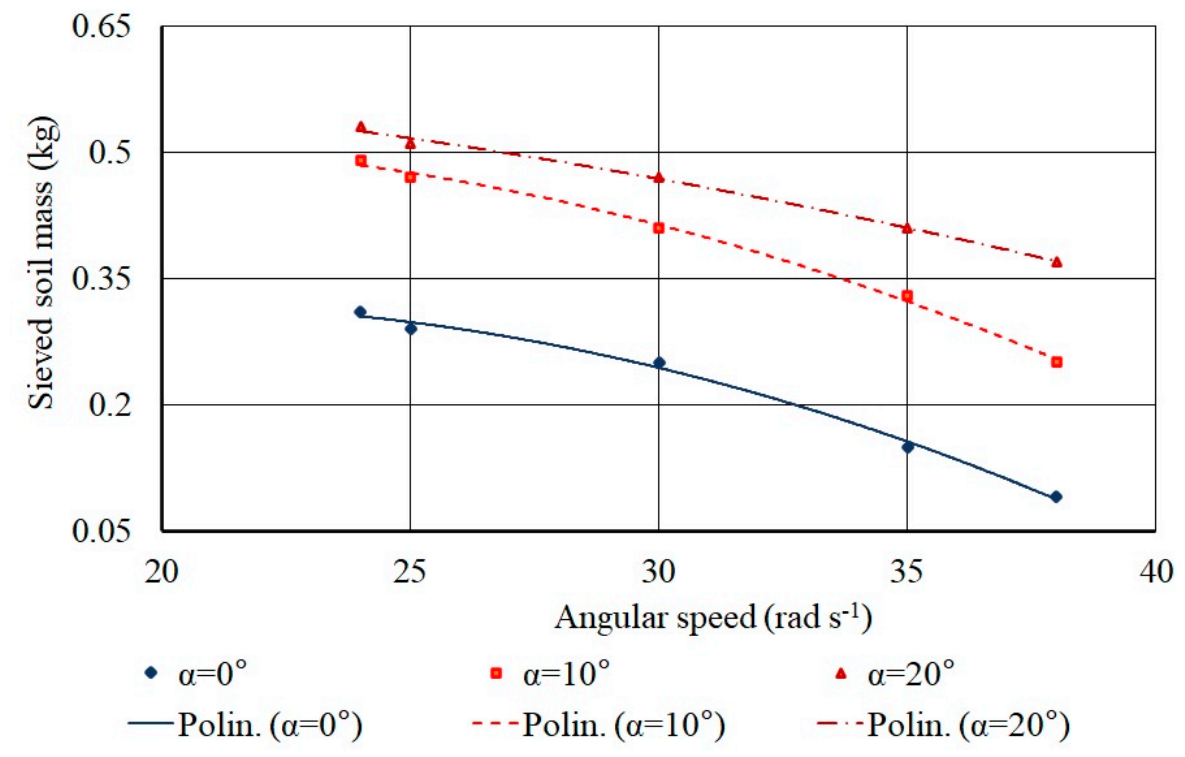

Figure 8. Sieved soil mass $\Delta M$ through the cleaner versus the angular speed $\omega$ of the spirals at different inclination angle $\alpha$ of the cleaner to the horizon.

Table 2. Regression functions, $\mathrm{R}^{2}$ value and $e$ value, concerning the soil change in mass $\Delta M$ upon the angular speed $\omega$ of the spirals, for different inclination angles $\alpha$ of the cleaner.

\begin{tabular}{cccc}
\hline Inclination & Polynomial Regression & $\mathbf{R}^{\mathbf{2}}$ & $\boldsymbol{e}$ \\
\hline$\alpha=0^{\circ}$ & $\Delta M=-0.0007 \omega^{2}+0.0258 \omega+0.0693$ & 0.9951 & $-8.44 \times 10^{-5}$ \\
$\alpha=10^{\circ}$ & $\Delta M=-0.0006 \omega^{2}+0.0197 \omega+0.3473$ & 0.9964 & $+4.32 \times 10^{4}$ \\
$\alpha=20^{\circ}$ & $\Delta M=-0.0002 \omega^{2}+0.0013 \omega+0.6085$ & 0.9961 & $-1.23 \times 10^{4}$ \\
\hline
\end{tabular}

As it is evident from Figure 8, the mass $\Delta M$ of the soil sifted through the cleaner spirals decreases slowly as the angular speed $\omega$ of rotation of the cleaner spirals increases. Furthermore, at the beginning, there is a gradual decrease in mass $\Delta M$ of the sifted soil until an angular velocity $\omega$, equal to $30 \mathrm{rad} \mathrm{s}^{-1}$, is reached. With a further increase in the angular speed $\omega$ of the spirals, a sharper decrease in mass $\Delta M$, sifted through the cleaner, starts, i.e., the separating ability of the spiral-type potato cleaner from admixtures decreases.

This is in agreement with previous studies [32,33] and completely confirmed by the results of the theoretical investigations, since, with an increase in the angular speed $\omega$ of rotation of the spirals, the contact time $t$ of the supplied potato tuber heap and other soil clods on the surface of the spirals decreases, as a result of which most clods of soil (especially of large sizes), receiving the initial speed of the motion from the helices of the spirals, do not have time to lose mass under the action of external forces from the side of the helices of the spirals.

Furthermore, the graphs of Figure 9 highlight that by increasing the angle of inclination $\alpha$ of the spiral-type cleaner to the horizon, the mass of the soil sifted through the spirals of the cleaner also increases significantly. This result agrees with conclusions present in literature [32] and confirms the correctness of the theoretical data that we have obtained as well. In this case, the force component of the weight of the soil clod, pressing it to the helix of the spiral (from its side), increases, which increases not only the speed of the forward motion of the clod of soil created by the helices of the spiral (due to 
reduced slip), but also contributes to a more intense destruction of the clod, the loss of its mass and screening down beyond the cleaner, thus recovering fertile soil.

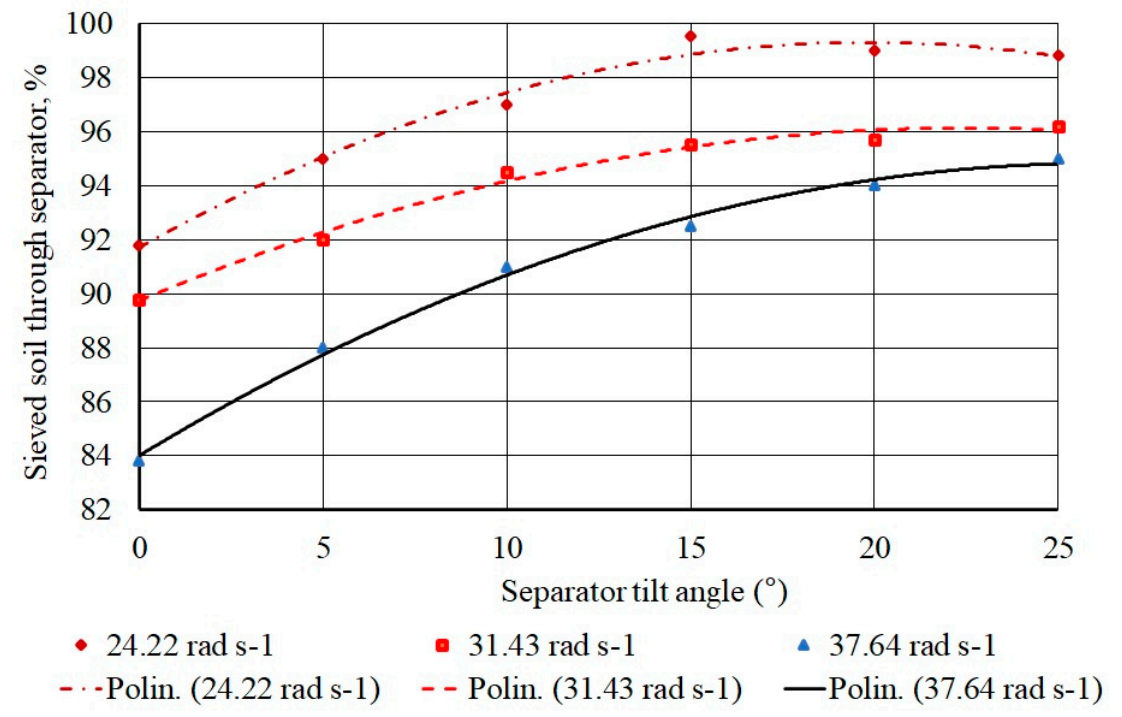

Figure 9. Screening ability of the cleaner $\mu$ versus the angle of inclination $\alpha$ to the horizon at different angular speeds $\omega$ of the spirals.

Figure 9 shows the dependences of the screening ability of the cleaner $\mu$, that is, the percentage of the soil sifted through the cleaner spirals, upon its angle of inclination $\alpha$ to the horizon at various angular speeds $\omega$ of the spirals. On the subject, Table 3 reports, for each considered angular speed $\omega$ of the spirals, the second-order polynomial regression with regard to the screening ability of the cleaner $\mu$, upon its angle of inclination $\alpha$, the corresponding $\mathrm{R}^{2}$ value and residual average value $e$.

Table 3. Regression functions, $\mathrm{R}^{2}$ value and $e$ value, relating to the screening ability of the cleaner $\mu$ upon the inclination $\alpha$ to the horizon, for different angular speeds $\omega$ of the spirals.

\begin{tabular}{|c|c|c|c|}
\hline Angular Speed ( $\left.\mathrm{rad} \mathrm{s}^{-1}\right)$ & Polynomial Regression & $\mathbf{R}^{2}$ & $e$ \\
\hline$\omega=24.22$ & $\mu=-0.0193 \alpha^{2}+0.765 \alpha+91.707$ & 0.9839 & +0.0033 \\
\hline$\omega=31.43$ & $\mu=-0.0126 \alpha^{2}+0.5681 \alpha+89.746$ & 0.9893 & -0.0101 \\
\hline$\omega=37.64$ & $\mu=-0.0157 \alpha^{2}+0.8243 \alpha+84.014$ & 0.9953 & -0.0035 \\
\hline
\end{tabular}

The graphs of this Figure point out that, with an increase in the angle of inclination $\alpha$ of the cleaner to the horizon to $15^{\circ}$, a significant increase in the optimization parameter is observed. With a further increase in this angle $\alpha$, the change in the percentage of the soil sifted through the cleaner spirals is insignificant, and there is reason to argue that, in the future, this indicator will have a constant value. This also confirms the previously obtained results of the theoretical research.

Figure 10 presents dependences of the specific intensity of the soil separation $q_{n}$ through the spiral-type cleaner upon its angle of inclination $\alpha$ to the horizon at various angular speeds $\omega$ of the spirals. On the subject, Table 4 reports, for each studied angular speed $\omega$ of the spirals, the second-order polynomial regression about the specific intensity of the soil separation $q_{n}$, upon the inclination $\alpha$ of the cleaner, the corresponding $\mathrm{R}^{2}$ value and residual average value $e$. 


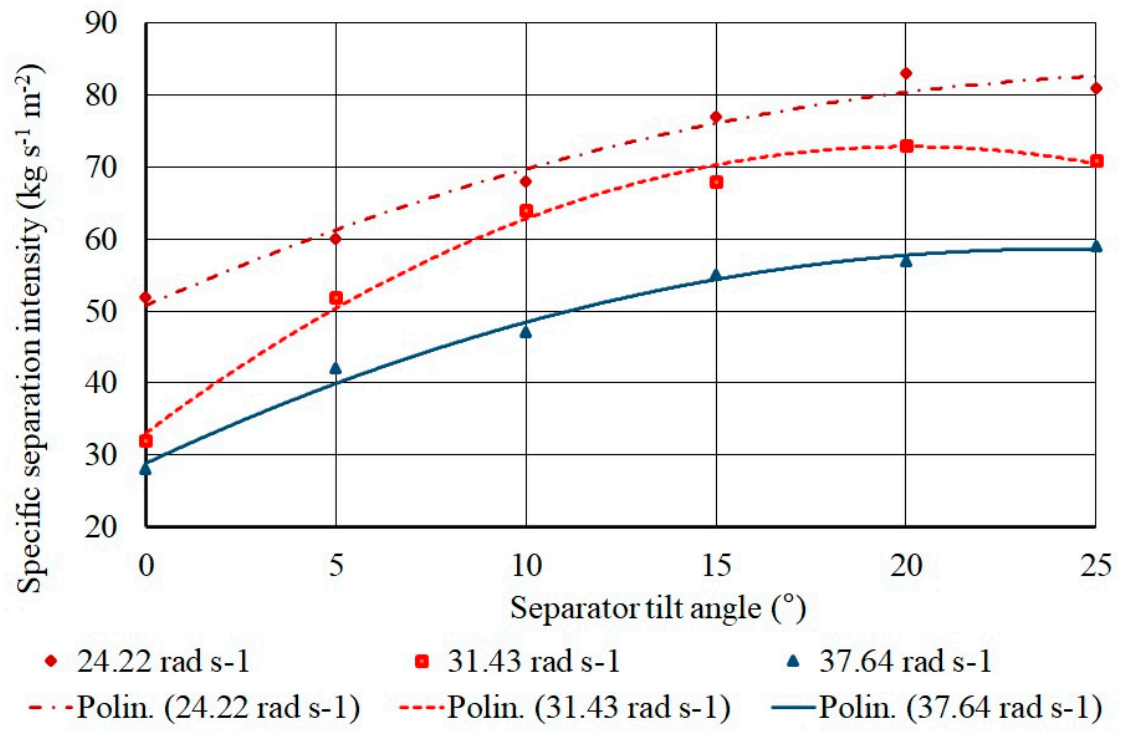

Figure 10. Specific intensity $q_{n}$ of the soil separation through the cleaner versus the angle of inclination $\alpha$ to the horizon at different angular speeds $\omega$ of rotation of the spirals.

Table 4. Regression functions, $\mathrm{R}^{2}$ value and $e$ value, regarding the specific intensity of the soil separation $q_{n}$ of the cleaner upon its inclination $\alpha$ to the horizon, for different angular speeds $\omega$ of the spirals.

\begin{tabular}{|c|c|c|c|}
\hline Angular Speed $\left(\operatorname{rad~s}{ }^{-1}\right)$ & Polynomial Regression & $\mathbf{R}^{2}$ & $e$ \\
\hline$\omega=24.22$ & $q_{n}=0.0414 \alpha^{2}+2.31 \alpha+50.786$ & 0.9787 & -0.0065 \\
\hline$\omega=31.43$ & $q_{n}=-0.0986 \alpha^{2}+3.9614 \alpha+33.071$ & 0.9913 & +0.0069 \\
\hline$\omega=37.64$ & $q_{n}=-0.0514 \alpha^{2}+2.4743 \alpha+28.857$ & 0.9880 & -0.0067 \\
\hline
\end{tabular}

The increase in the specific intensity of the soil separation $q_{n}$ under the impact of the growing angle of inclination $\alpha$ of the cleaner to the horizon is of a smoother nature in comparison with the dependences on these factors of the percentage of the sifted soil (Figure 9). Increasing the angular speed $\omega$ of the spirals also reduces this indicator $q_{n}$, i.e., the specific intensity of the soil separation. This indicator, obtained by the results of the experimental investigation, also confirms the main results of the theoretical research.

Basically, the reported theorical and experimental data show the operational usefulness of the new spiral-type potato cleaner of the design developed by us in the recovery of fertile soil. The effectiveness in recovering fertile soil during the harvesting phase greatly reduces the environmental impact, assuming a significant role in the context of sustainable potato cultivation [34].

\section{Conclusions}

A mathematical model of the sifting process of the soil clods, falling onto the spiral-type potato cleaner together with a heap of potato tubers, dug from the soil, was developed for a case when the soil clod (particle) contacts the spiral helices of the separator at two points.

A new differential equation is obtained that allows one to describe the process of reducing the mass of soil clods entering the spiral surface of the separator as a function of time. In this case, the indicated decrease in the mass of the soil clods occurs when they move along the spiral. The changes in mass $m$ of the clod of soil in time $t$, obtained as a result of the numerical solution of the developed mathematical model, confirm its adequacy and allow for determining the rational parameters of the developed spiral potato heap separator. From an analysis of the obtained results, it can be concluded that the structural and kinematic parameters, considered as the basics, are: the angular speed $\omega$ of rotation of the spirals of springs in the range from 20.0 to $30.0 \mathrm{rad} \mathrm{s}^{-1}$ with a radius $R$ of spirals within the interval from 0.12 to $0.15 \mathrm{~m}$. The results of the experimental tests completely confirmed the data obtained during 
the theoretical research of sifting the clod of soil through the new spiral-type potato cleaner from admixtures. Therefore, the machine developed by the authors performs its task properly safeguarding fertile soil, with a better sustainability of the potato harvesting phase.

Author Contributions: Conceptualization, V.B., S.P., and S.I.; methodology, V.B., S.P., S.I., Z.R., I.F., and F.S.; formal analysis, investigation and data curation, S.I., Z.R., I.F., and F.S.; writing-original draft preparation, V.B. S.P., S.I., and I.F.; writing - review and editing, V.B. and S.P.; supervision, V.B. and S.P. All authors have read and agreed to the published version of the manuscript

Funding: This research received no external funding.

Conflicts of Interest: The authors declare no conflict of interest.

\section{Appendix A}

The differential equation:

$$
m \frac{d \bar{V}}{d t}=\bar{G}+\bar{N}_{1}+\bar{N}_{2}+F_{1}+\bar{F}_{2}+\bar{T}-\bar{V} \frac{d m}{d t}
$$

can be presented in the form of its projections on the $x, y$, and $z$ coordinate axes of the absolute coordinate system $x \mathrm{Oyz}$.

Under the condition of all the external forces acting upon body $M$ of a variable mass, Equation (8) in projections onto the indicated axes of the absolute coordinate system $x \mathrm{Oyz}$ gives the following system of differential equations:

$$
\left\{\begin{array}{c}
m \ddot{x}=-N_{1} \cdot \sin \psi_{1} \cdot \cos \left(\alpha_{0}+\alpha\right)-N_{2} \cdot \sin \psi_{2} \cdot \cos \left(\alpha_{0}+\alpha\right)+ \\
+F_{1} \cdot \cos \gamma \cdot \sin \left(\alpha_{0}+\alpha\right)+F_{2} \cdot \cos \gamma \cdot \sin \left(\alpha_{0}+\alpha\right)-T \cdot \cos \left(\alpha_{0}+\alpha\right)-\dot{x} \frac{d m}{d t} \\
m \ddot{y}=-N_{1} \cdot \sin \psi_{1} \cdot \sin \left(\alpha_{0}+\alpha\right)+N_{2} \cdot \sin \psi_{2} \cdot \sin \left(\alpha_{0}+\alpha\right)+ \\
+F_{1} \cdot \cos \gamma \cdot \cos \left(\alpha_{0}+\alpha\right)+F_{2} \cdot \cos \gamma \cdot \cos \left(\alpha_{0}+\alpha\right)+T \cdot \sin \left(\alpha_{0}+\alpha\right)-\dot{y} \frac{d m}{d t}-m g \\
m \ddot{z}=N_{1} \cdot \cos \psi_{1}-N_{2} \cdot \cos \psi_{2}+F_{1} \cdot \sin \gamma-F_{2} \cdot \sin \gamma-\dot{z} \frac{d m}{d t}
\end{array}\right.
$$

Considering that, in a general case, body $M$ of variable mass (i.e., a clod of soil) can move (slip) relative to the cylindrical surface of the spiral, angle $a$, indicated above, is equal to:

$$
\alpha=(\omega t+\varphi)
$$

where

$\varphi$ is the angle by which the body $M$ of variable mass can move in the cross-section of the spiral relative to its surface.

The indicated angle $\varphi$ depends on many factors, especially considering the oscillating motion of the end of the cleaning spiral, which may occur due to a variable load from the incoming mass of the heap or due to the presence of eccentricity because of the deflection of the longitudinal axis of the spiral. The value of this angle $\varphi$ may vary both in value and direction.

If we take into account the previously obtained analytical Equations (1)-(3), as well as the above assumptions regarding angle $\alpha$ which has value $\alpha=(\omega t+\varphi)$, the system of differential equations (A2) can be transformed into this form:

$$
\left\{\begin{array}{c}
m \ddot{x}=-N_{1} \cdot \sin \psi_{1} \cdot \cos \left(\alpha_{0}+\omega t+\varphi\right)-N_{2} \cdot \sin \psi_{2} \cdot \cos \left(\alpha_{0}+\omega t+\varphi\right)+ \\
+f N_{1} \cdot \cos \gamma \cdot \sin \left(\alpha_{0}+\omega t+\varphi\right)+f N_{2} \cdot \cos \gamma \cdot \sin \left(\alpha_{0}+\omega t+\varphi\right)- \\
-m \cdot \omega^{2} \cdot A \cdot \sin \left(\alpha_{0}+\omega t\right) \cdot \cos \left(\alpha_{0}+\omega t+\varphi\right)-\dot{x} \frac{d m}{d t} \\
m \ddot{y}=N_{1} \cdot \sin \psi_{1} \cdot \sin \left(\alpha_{0}+\omega t+\varphi\right)-N_{2} \cdot \sin \psi_{2} \cdot \sin \left(\alpha_{0}+\omega t+\varphi\right)+ \\
+f N_{1} \cdot \cos \gamma \cdot \cos \left(\alpha_{0}+\omega t+\varphi\right)+f N_{2} \cdot \cos \gamma \cdot \cos \left(\alpha_{0}+\omega t+\varphi\right)+ \\
+m \cdot \omega^{2} \cdot A \cdot \sin \left(\alpha_{0}+\omega t\right) \cdot \sin \left(\alpha_{0}+\omega t+\varphi\right)-\dot{y} \frac{d m}{d t}-m g \\
m \ddot{z}=N_{1} \cdot \cos \psi_{1}-N_{2} \cdot \cos \psi_{2}-f N_{1} \cdot \sin \gamma-f N_{2} \cdot \sin \gamma-\dot{z} \frac{d m}{d t}
\end{array}\right.
$$


Thus, there is finally an obtained system of differential equations (A4) of the motion of body $M$ of variable mass (i.e., a clod of soil) in a general form.

The system of differential equations (A4) is designed to describe the motion of a single clod of soil along the surface of the cleaning spiral. However, considering that the clod of soil studied is in a stream of the heap, i.e., surrounded by other elements of the heap, the mass of which in their sum (and hence their inertial properties) significantly exceeds the mass of the studied single clod of soil, and their total friction force also significantly exceeds the friction force of the considered clod of soil, we can assume at the first approximation that this clod of soil does not significantly slip in the cross-section of the spiral, which means that it is possible to assume with sufficient accuracy for practice that angle $\varphi \approx 0$. Then, angle $\alpha$ is equal to $\alpha=\omega t$, which simplifies the system of differential equations (A4). Therefore, provided that $\varphi=0$, we obtain such a system of differential equations of the motion of a clod of soil $M$ along the spiral surface:

$$
\left\{\begin{array}{c}
m \ddot{x}=-N_{1} \cdot \sin \psi_{1} \cdot \cos \left(\alpha_{0}+\omega t\right)-N_{2} \cdot \sin \psi_{2} \cdot \cos \left(\alpha_{0}+\omega t\right)+ \\
+f N_{1} \cdot \cos \gamma \cdot \sin \left(\alpha_{0}+\omega t\right)+f N_{2} \cdot \cos \gamma \cdot \sin \left(\alpha_{0}+\omega t\right)- \\
-m \cdot \omega^{2} \cdot A \cdot \sin \left(\alpha_{0}+\omega t\right) \cdot \cos \left(\alpha_{0}+\omega t\right)-\dot{x} \frac{d m}{d t} \\
m \ddot{y}=N_{1} \cdot \sin \psi_{1} \cdot \sin \left(\alpha_{0}+\omega t\right)+N_{2} \cdot \sin \psi_{2} \cdot \sin \left(\alpha_{0}+\omega t\right)+ \\
+f N_{1} \cdot \cos \gamma \cdot \cos \left(\alpha_{0}+\omega t\right)+f N_{2} \cdot \cos \gamma \cdot \cos \left(\alpha_{0}+\omega t\right)+ \\
\quad+m \cdot \omega^{2} \cdot A \cdot \sin ^{2}\left(\alpha_{0}+\omega t\right)-\dot{y} \frac{d m}{d t}-m g \\
m \ddot{z}=N_{1} \cdot \cos \psi_{1}-N_{2} \cdot \cos \psi_{2}-f N_{1} \cdot \sin \gamma-f N_{2} \cdot \sin \gamma-\dot{z} \frac{d m}{d t}
\end{array}\right.
$$

To assess the rate of decrease in mass $m$ of the clod of soil $M$ over time $t$, i.e., value $\frac{d m}{d t}$, we determine this quantity from the system of differential equations (A5). At first, from the first two equations of system (A5), we find equations for the derivative $\frac{d m}{d t}$ and, equating their values, after a series of transformations, we obtain the following dependence:

$$
\begin{gathered}
f\left(N_{1}+N_{2}\right)=\left\{\frac{m \ddot{x}}{\dot{x}}-\frac{m \ddot{y}}{\dot{y}}+m \cdot \omega^{2} \cdot A \cdot\left[\frac{\sin 2\left(\alpha_{0}+\omega t\right)}{2 \dot{x}}+\frac{\sin ^{2}\left(\alpha_{0}+\omega t\right)}{\dot{y}}\right]-\frac{m g}{\dot{y}}\right. \\
\left.+\left(N_{1} \cdot \sin \psi_{1}+N_{2} \cdot \sin \psi_{2}\right)\left[\frac{\cos \left(\alpha_{0}+\omega t\right)}{\dot{x}}+\frac{\sin \left(\alpha_{0}+\omega t\right)}{\dot{y}}\right]\right\} \\
\cdot\left\{\cos \gamma \cdot\left[\frac{\sin \left(\alpha_{0}+\omega t\right)}{\dot{x}}-\frac{\cos \left(\alpha_{0}+\omega t\right)}{\dot{y}}\right]\right\}^{-1}
\end{gathered}
$$

Next, we transform the third equation of system (A5) to the following form:

$$
\frac{d m}{d t}=\frac{1}{\dot{z}}\left[-m \ddot{z}+N_{1} \cdot \cos \psi_{1}-N_{2} \cdot \cos \psi_{2}-f\left(N_{1}+N_{2}\right) \cdot \sin \gamma\right]
$$

By substituting into Equation (A7) instead of $f\left(N_{1}+N_{2}\right)$ its value, according to Equation (A6), we finally obtain a differential equation for the change in the mass $m$ of the clod of soil $M$ lying between two adjacent helices of one spiral and contacting it at points $K_{1}$ and $K_{2}$ over time $t$ :

$$
\begin{aligned}
& \frac{d m}{d t}=-\frac{m \ddot{z}}{\dot{z}}+\frac{N_{1} \cdot \cos \psi_{1}-N_{2} \cdot \cos \psi_{2}}{\dot{z}} \\
- & \frac{\tan \gamma}{\dot{z}}\left\{\frac{m \ddot{x}}{\dot{x}}-\frac{m \ddot{y}}{\dot{y}}+m \cdot \omega^{2} \cdot A \cdot\left[\frac{\sin 2\left(\alpha_{0}+\omega t\right)}{2 \dot{x}}+\frac{\sin ^{2}\left(\alpha_{0}+\omega t\right)}{\dot{y}}\right]-\frac{m g}{\dot{y}}\right. \\
+ & \left.\left(N_{1} \cdot \sin \psi_{1}-N_{2} \cdot \sin \psi_{2}\right)\left[\frac{\cos \left(\alpha_{0}+\omega t\right)}{\dot{x}}+\frac{\sin \left(\alpha_{0}+\omega t\right)}{\dot{y}}\right]\right\} \\
\cdot & {\left[\frac{\sin \left(\alpha_{0}+\omega t\right)}{\dot{x}}-\frac{\cos \left(\alpha_{0}+\omega t\right)}{\dot{y}}\right]^{-1} }
\end{aligned}
$$

Taking into account the previous assumption about a sufficiently small displacement (slippage) of the clod of soil $M$ in the cross-section of the cleaning spiral relative to its surface, we can consider that the motion of this body along the surface of the spiral can be described just in this way. Since the motion of the clod of soil $M$ takes place using the turn of a cleaning spiral, the equation of which is 
an equation of the helical line in the parametric form, then, according to [22], it can be represented as follows:

$$
\left\{\begin{array}{c}
x=R \cdot \cos \left(\alpha_{0}+\omega t\right) \\
y=R \cdot \sin \left(\alpha_{0}+\omega t\right) \\
z=\frac{S}{2 \pi} \cdot\left(\alpha_{0}+\omega t\right)
\end{array}\right.
$$

In addition, it is possible to determine the projections of the velocity and acceleration of the movement of the clod of soil $M$ on the axis of the Cartesian coordinate system $x, y$ and $z$.

After differentiating Equations (A9) for time $t$, we define in the adopted coordinate system $x \mathrm{Oyz}$ the projections of the velocity of the movement of the particular body $M$ onto the corresponding coordinate axes:

$$
\left\{\begin{array}{c}
\dot{x}=-\omega R \cdot \sin \left(\alpha_{0}+\omega t\right) \\
\dot{y}=\omega R \cdot \cos \left(\alpha_{0}+\omega t\right) \\
\dot{z}=\frac{s}{2 \pi} \cdot \omega
\end{array}\right.
$$

After the differentiation by time $t$ of Equation (A10), we obtain the projections of the acceleration of the movement of the helix of the cleaning spiral onto the data of the coordinate axis:

$$
\left\{\begin{array}{c}
\ddot{x}=-R \omega^{2} \cdot \cos \left(\alpha_{0}+\omega t\right) \\
\ddot{y}=-R \omega^{2} \cdot \sin \left(\alpha_{0}+\omega t\right) \\
\dot{z}=0
\end{array}\right.
$$

Since, as mentioned above, body $M$ moves along the working surface of the helix of the cleaning spiral without slipping, that is, there is every reason to assert that the acceleration of body $M$ is equal to the acceleration of the helix of the spiral itself on which it is situated at the given moment of time $t$.

By substituting the obtained values (A11) and (A10) into expression (A8), we finally obtain the differential equation in the following form:

$$
\begin{aligned}
& \frac{d m}{d t}=\frac{2 \pi\left(N_{1} \cos \psi_{1}-N_{2} \cos \psi_{2}\right)}{S \omega}+\frac{\pi \cdot R \cdot \tan \gamma}{S} \\
& \cdot\left\{m \cdot \omega \cdot\left[\frac{1}{\tan \left(\alpha_{0}+\omega t\right)}+\tan \left(\alpha_{0}+\omega t\right)\right]+\frac{m \cdot \omega \cdot A}{R}\right. \\
& \cdot\left[\frac{\sin ^{2}\left(\alpha_{0}+\omega t\right)}{\cos \left(\alpha_{0}+\omega t\right)}-\cos \left(\alpha_{0}+\omega t\right)\right]-\frac{m \cdot g}{\omega \cdot R \cdot \cos \left(\alpha_{0}+\omega t\right)} \\
& \left.+\left(N_{1} \sin \psi_{1}+N_{2} \sin \psi_{2}\right) \cdot \frac{1}{\omega \cdot R} \cdot\left[\tan \left(\alpha_{0}+\omega t\right)-\frac{1}{\tan \left(\alpha_{0}+\omega t\right)}\right]\right\}
\end{aligned}
$$

which models the change in the mass of the soil clod $M$ during time $t$, due to the applied forces to it.

\section{References}

1. Mensah, J. Sustainable development: Meaning, history, principles, pillars, and implications for human action: Literature review. Cogent Soc. Sci. 2019, 5, 1653531. [CrossRef]

2. Hou, D.; Bolan, N.S.; Tsang, D.C.; Kirkham, M.B.; O'Connor, D. Sustainable soil use and management: An interdisciplinary and systematic approach. Sci. Total. Environ. 2020, 729, 138961. [CrossRef] [PubMed]

3. Sawicka, B.; Hameed, T.S. Farmers' knowledge of sustainable potato cultivation techniques in Poland. Agron. Sci. 2019, 74, 81-98. [CrossRef]

4. Esehaghbeygi, A.; Besharati, S. Potato variety and storage for tuber sensitivity in bruising. World Appl. Sci. J. 2009, 7, 1504-1507.

5. Bulgakov, V.; Pascuzzi, S.; Anifantis, A.S.; Santoro, F. Oscillations analysis of front-mounted beet topper machine for biomass harvesting. Energies 2019, 12, 2774. [CrossRef]

6. Scott, G.J. Maps, models, and muddles: World trends and patterns in potatoes revisited. Potato Res. 2002, 45, 45-77. [CrossRef]

7. Keijbets, M.J.H. Potato processing for the consumer: Developments and future challenges. Potato Res. 2008, 51, 271-281. [CrossRef] 
8. Polacchi, W.; Weisell, R.; Marroni, S.; Mazar, I. Derivation of nutrient values for FAO statistical databases. J. Food Compos. Anal. 2002, 15, 515-522. [CrossRef]

9. Adamchuk, V.; Prysyazhnyi, V.; Ivanovs, S.; Bulgakov, V. Investigations in technological method of growing potatoes under mulch of straw and its effect on the yield. In Proceedings of the 15th International Scientific Conference Engineering for Rural Development, Jelgava, Latvia, 25-27 May 2016; pp. 1098-1103.

10. Bentini, M.; Caprara, C.; Martelli, R. Harvesting damage to potato tubers by analysis of impacts recorded with an instrumented sphere. Biosyst. Eng. 2006, 94, 75-85. [CrossRef]

11. Al-Mallahi, A.; Kataoka, T.; Okamoto, H.; Shibata, Y. Detection of potato tubers using an ultraviolet imaging-based machine vision system. Biosyst. Eng. 2010, 105, 257-265. [CrossRef]

12. Ichiki, H.; Nguyen Van, N.; Yoshinaga, K. Stone-cold separation and its application to potato cultivation in Hokkaido; Bio-oriented Technology Research Advancement Institution: 2013. Eng. Agric. Environ. Food 2013, 6, 77-85.

13. Guerrieri, A.S.; Anifantis, A.S.; Santoro, F.; Pascuzzi, S. Study of a large square baler with innovative technological systems that optimize the baling effectiveness. Agriculture 2019, 9, 86. [CrossRef]

14. Bulgakov, V.; Ivanovs, S.; Adamchuk, V.; Ihnatiev, Y. Investigation of the influence of the parameters of the experimental spiral potato heap separator on the quality of work. Agron. Res. 2017, 15, 044-054.

15. Bulgakov, V.; Pascuzzi, S.; Nikolaenko, S.; Santoro, F.; Anifantis, A.S.; Olt, J. Theoretical study on sieving of potato heap elements in spiral separator. Agron. Res. 2019, 17, 33-48.

16. Pascuzzi, S.; Santoro, F. Evaluation of farmers' OSH hazard in operationnearby mobile telephone radio base stations. Eng. Rural Dev. 2017, 16, 748-755. [CrossRef]

17. Santoro, F.; Anifantis, A.S.; Ruggiero, G.; Zavadskiy, V.; Pascuzzi, S. Lightning protection systems suitable for stables: A case study. Agriculture 2019, 9, 72. [CrossRef]

18. Pascuzzi, S.; Santoro, F. Analysis of the almond harvesting and hulling mechanization process: A case study. Agriculture 2017, 7, 100. [CrossRef]

19. Cerruto, E.; Giuseppe, M.; Santoro, F.; Pascuzzi, S. Operator dermal exposure to pesticides in tomato and strawberry greenhouses from hand-held sprayers. Sustainability 2018, 10, 2273. [CrossRef]

20. Pascuzzi, S.; Blanco, I.; Anifantis, A.S.; Scarascia Mugnozza, G. Hazards assessment and technical actions due to the production of pressured hydrogen within a pilot photovoltaic-electrolyzer-fuel cell power system for agricultural equipment. J. Agric. Eng. 2016, 47, 89-93.

21. Pascuzzi, S.; Cerruto, E. An innovative pneumatic electrostatic sprayer useful for tendone vineyards. J. Agric. Eng. 2015, 46, 123-127. [CrossRef]

22. Vasilenko, P.M. Introduction to Agricultural Mechanics; Selhoz Obrazovanie: Kiev, Ukraine, 1996; p. 234. (In Ukrainian)

23. Bulgakov, V.; Holovach, I.; Ruzhylo, Z.; Pascuzzi, S.; Santoro, F.; Anifantis, A.S. Cleaner of a Heap of Root Crops from Impuritie. Patent UA 120234 A 01 D 33/08, B 08 B 7/04, 25 October 2017.

24. Bulgakov, V.; Pascuzzi, S.; Adamchuk, V.; Ivanovs, S.; Pylypaka, S. A theoretical study of the limit path of the movement of a layer of soil along the plough mouldboard. Soil Tillage Res. 2019, 195, 104406. [CrossRef]

25. Bulgakov, V.; Pascuzzi, S.; Adamchuk, V.; Kuvachov, V.; Nozdrovický, L. Theoretical study of transverse offsets of wide span tractor working implements and their influence on damage to row crops. Agriculture 2019, 9, 144. [CrossRef]

26. Bulgakov, V.; Pascuzzi, S.; Ivanovs, S.; Kaletnik, G.; Yanovich, V. Angular oscillation model to predict the performance of a vibratory ball mill for the fine grinding of grain. Biosyst. Eng. 2018, 171, 155-164. [CrossRef]

27. Bulgakov, V.; Pascuzzi, S.; Nadykto, V.; Ivanovs, S. A Mathematical model of the plane-parallel movement of an asymmetric machine-and-tractor aggregate. Agriculture 2018, 8, 151. [CrossRef]

28. Bulgakov, V.; Pascuzzi, S.; Ivanovs, S.; Nadykto, V.; Nowak, J. Kinematic discrepancy between driving wheels evaluated for a modular traction device. Biosyst. Eng. 2020, 196, 88-96. [CrossRef]

29. Bulgakov, V.; Pascuzzi, S.; Santoro, F.; Anifantis, A.S. Mathematical model of the plane-parallel movement of the self-propelled root-harvesting machine. Sustainability 2018, 10, 3614. [CrossRef]

30. Greenspan, D.; Carnahan, B.; Luther, H.A.; Wilkes, J.O. Applied numerical methods. Math. Comput. 1970, 24, 750. [CrossRef]

31. Bulgakov, V.; Pascuzzi, S.; Ivanovs, S.; Santoro, F.; Anifantis, A.S.; Ihnatiev, I. Performance assessment of front-mounted beet topper machine for biomass harvesting. Energies 2020, 13, 3524. [CrossRef] 
32. Mitrofanov, V.S. Physico-mechanical properties of potatoes. In Theory, Design and Production of Agricultural Machinery; Mechanical Engineering: Moscow, Russia, 1997; Volume 5, p. 511. (In Russian)

33. Petrov, G.D. Potato Harvesting Machines; Mechanical Engineering: Moscow, Russia, 2004; p. 320. (In Russian)

34. Birch, P.R.J.; Bryan, G.J.; Fenton, B.; Gilroy, E.M.; Hein, I.; Jones, J.T.; Prashar, A.; Taylor, M.A.; Torrance, L.; Toth, I.K. Crops that feed the world 8: Potato: Are the trends of increased global production sustainable? Food Secur. 2012, 4, 477-508. [CrossRef]

Publisher's Note: MDPI stays neutral with regard to jurisdictional claims in published maps and institutional affiliations.

(C) 2020 by the authors. Licensee MDPI, Basel, Switzerland. This article is an open access article distributed under the terms and conditions of the Creative Commons Attribution (CC BY) license (http://creativecommons.org/licenses/by/4.0/). 